\title{
Mendelization and Molecular Mapping of a Large-effect QTL Conferring Durable Adult-plant Resistance to Stripe Rust in a Chinese Wheat Landrace 'Gaoxianguangtoumai'
}

\section{Yuqi Wang}

Sichuan Agricultural University

\section{Fengying Liang}

Sichuan Agricultural University

\section{Fangnian Guan}

Sichuan Agricultural University

\section{Fangjie Yao}

Sichuan Agricultural University

Long Li

Sichuan Agricultural University

\section{Xuyang Zhao}

Sichuan Agricultural University

Luyao Duan

Sichuan Agricultural University

Yu Wu

Sichuan Agricultural University

Hao Li

Sichuan Agricultural University

Wei Li

Sichuan Agricultural University

Qiantao Jiang

Sichuan Agricultural University

Yuming Wei

Sichuan Agricultural University

Jian Ma

Sichuan Agricultural University

Pengfei Qi

Sichuan Agricultural University

Mei Deng

Sichuan Agricultural University

Youliang Zheng

Sichuan Agricultural University

Houyang Kang

Sichuan Agricultural University

\section{Yunfeng Jiang}

Sichuan Agricultural University

Guoyue Chen ( $\nabla$ gychen@sicau.edu.cn )

Triticeae Research Institute https://orcid.org/0000-0001-7710-1684 


\section{Research Article}

Keywords: adult-plant resistance (APR), QTL, stripe rust, Chinese wheat landrace, Genetic mapping, near-isogenic lines (NILs)

Posted Date: June 15th, 2021

DOI: https://doi.org/10.21203/rs.3.rs-603248/v1

License: (c) (1) This work is licensed under a Creative Commons Attribution 4.0 International License. Read Full License 


\section{Abstract}

The Chinese wheat landrace 'Gaoxianguangtoumai' (GX) has exhibited a high degree of adult-plant resistance (APR) to stripe rust in field environments for more than a decade. To reveal the genetic basis for APR to stripe rust in GX, a set of $249 F_{6: 8}$ recombinant inbred lines (RILs) was developed from a cross between GX and the susceptible cultivar 'Taichung 29'. The parents and RILs were evaluated for disease severity at the adult-plant stage in field environments by artificial inoculation with the currently predominant Chinese Puccinia striiformis f. sp. tritici races during three cropping seasons, and genotyped using the Wheat 55K single-nucleotide polymorphism (SNP) array to construct a genetic map with 1,871 SNP markers. Two stable APR quantitative trait loci (QTL), QYr.GX-2AS and QYr.GX-7DS from GX, were detected on chromosomes 2AS and 7DS, which explained $15.5-27.0 \%$ and $9.6-15.6 \%$ of the total phenotypic variation, respectively. Compared with published genes and QTL, QYr.GX-7DS is likely Yr18, whereas QYr.GX-2AS is probably novel. Haplotype analysis revealed that QYr.GX-2AS is likely to be rare which present in $5.3 \%$ of the 325 surveyed Chinese wheat landraces. By analyzing a near-isogenic line population, QYr.GX-2AS was further mapped to an interval with a physical distance of about $1.37 \mathrm{Mb}$ and co-segregated with a Kompetitive allele-specific PCR (KASP) marker. Furthermore, three tightly linked KASP markers were highly polymorphic among 109 Chinese wheat cultivars. The short physical interval and tightly linked KASP markers developed in this study will facilitate marker-assisted selection and map-based cloning of QYr.GX-2AS.

\section{Key Message}

QYr.GX-2AS, a novel adult-plant stripe rust resistance QTL on wheat chromosome 2AS derived from a Chinese landrace, behaves as a single Mendelian gene and provides more effective resistance than Yr18.

\section{Introduction}

Stripe rust (also known as yellow rust), caused by Puccinia striiformis f. sp. tritici (Pst), is among the most harmful and widespread obligate pathogens of common wheat (Triticum aestivum L.) worldwide (Knott 1989; Wellings 2011). China has the largest stripe rust epidemic area in the world (Zeng and Luo 2006; Chen et al. 2014), and frequent epidemics have been reported (Han and Kang 2018). Since the 1950s, four severe epidemics of wheat stripe rust have occurred in China in 1950, 1964, 1990, and 2002, resulting in yield losses of 6.0, 3.2, 1.8, and 1.4 million tonnes, respectively (Li and Zeng 2000; Wan et al. 2004). The main cause of the outbreaks is the emergence of new virulent races that overcome the widely deployed resistance genes (Chen and Kang 2017). At present, CYR32 and CYR34 are the most virulent and predominant Pst races in China (Liu et al. 2017; Wang et al. 2018). Continuous improvement in the resistance of wheat cultivars to cope with evolving races of Pst is a high priority to control stripe rust (Manickavelu et al. 2016).

To date, more than 300 genes or quantitative trait loci (QTL) for stripe rust resistance on the 21 wheat chromosomes have been reported (Rosewarne et al. 2013; McIntosh et al. 2018). In general, these resistance genes and QTL can be classified into two major classes: all-stage resistance (ASR) and adult-plant resistance (APR). ASR usually confers complete resistance during all growth stages and is simple to select during breeding. However, most ASR genes are race specific and encode nucleotide-binding and leucine-rich repeat (NLR) proteins, and therefore are effective against only a subset of Pst races. With regard to the dynamic rust pathogen populations of the virulent races, only a small number of the characterized ASR genes, such as Yr5 (Marchal et al. 2018), Yr15 (Klymiuk et al. 2018), Yr53 (Xu et al. 2013), Yr61 (Zhou et al. 2014), Yr65 (Cheng et al. 2014), and Yr69 (Hou et al. 2016), are still widely effective against currently dominant Pst race groups in China (SharmaPoudyal et al. 2013; Wu et al. 2018). In contrast, APR is effective starting at adult-plant growth stages and typically provides a degree of partial resistance, but it is usually non-race-specific and provides durable resistance to Pst. Of the three APR genes cloned to date, Yr18 encodes a putative ATP-binding cassette transporter (Krattinger et al. 2009), Yr36 encodes a kinase domain and a lipid-binding domain (Fu et al. 2009), and Yr46 encodes a predicted hexose transporter (Moore et al. 2015). These genes represent different protein families compared with classical ASR genes (the NLR family) and provide unique mechanisms effective against a broader range of pathogens. As an example, Yr18 has been globally used as a component of durable rust resistance in breeding programs and no evolution of increased virulence has been observed for

Page $3 / 20$ 
almost 100 years (Krattinger et al. 2009). To achieve a high degree of durable resistance, combining multiple APR genes into the same background has been considered as an important strategy for improvement of stripe rust resistance in wheat breeding.

Chinese wheat landraces are farmer-developed and maintained as traditional cultivars in China. These landraces harbor rich genetic diversity for stripe rust resistance. Numerous stripe rust genes or QTL have been identified, such as Yr1 (Bansal et al. 2010), Yr18 (Krattinger et al. 2009), Yr81 (Gessese et al. 2019), YrYL (Wu et al. 2016), YrBai (Ma et al. 2015), Yrqbc (Cao et al. 2020), QYr.caas-5AL (Lan et al. 2010), QYr.cau-6DL (Zhang et al. 2017), QYr.cau-2AL (Wang et al. 2019a), QYr.GTM-5DL (Wu et al. 2020), and QYr.AYH-5BL (Long et al. 2021). Recently, our research program evaluated more than 1000 Chinese wheat landrace accessions collected from all ten agro-ecological zones (Zhou et al. 2017) for responses to stripe rust in the greenhouse and the field under inoculation with selected Chinese predominant races of Pst (Cheng et al. 2019; Long et al. 2019; Yao et al. 2019, 2020; Ye et al. 2019; Wang et al. 2021). Many resistant accessions of Chinese wheat landraces continually display APR to stripe rust in field environments, providing a novel resistance resource for the breeding of wheat cultivars with durable resistance to stripe rust. The novel APR genes require further research for identification, validation, and mendelization to facilitate their use in wheat breeding.

Gaoxianguangtoumai (GX) is a spring wheat landrace from Sichuan Province in southwest China, which is a regional center for oversummering and overwintering of the stripe rust pathogen. This landrace has exhibited a high degree of APR to stripe rust in field environments for more than a decade, but little information is available on the genetic basis of resistance in this landrace. The objectives of the present study were to (1) identify the QTL conferring APR to stripe rust in a recombinant inbred line (RIL) population developed from the cross between GX and a susceptible cultivar, 'Taichung 29' (TC 29), (2) validate and mendelize the novel QTL in a near-isogenic line (NIL) derived population, and (3) develop tightly linked Kompetitive allele-specific PCR (KASP) markers for use in marker-assisted selection in breeding programs.

\section{Materials And Methods}

\section{Plant materials and races}

The Chinese wheat landrace GX (accession number ZM7854 in National Germplasm Bank, China (NGBC) and AS1579 in Triticeae Research Institute, Sichuan Agricultural University) originating from Sichuan Province, was crossed (as the female parent) with the highly stripe rust susceptible wheat cultivar TC 29 . In total, $249 \mathrm{~F}_{6: 8}$ RILs derived from a single $F_{1}$ seed were developed by single-seed descent. A NIL-derived population of 130 individuals $\left(F_{2}\right)$, derived from a residual heterozygous line selected from the GX $\times$ TC 29 RIL population $\left(\mathrm{F}_{8}\right)$ carrying heterozygous segments covering the QYr.GX-2AS region, was used for validation of QYr.GX-2AS. A collection of 325 Chinese wheat landraces genotyped with the $55 \mathrm{~K}$ single-nucleotide polymorphism (SNP) array was used for marker haplotype analysis (Zhou et al. 2017). A panel of 109 Sichuan wheat cultivars was used to determine the polymorphism of markers tightly linked with QYr.GX-2AS. The highly stripe rust susceptible wheat cultivars 'Mingxian 169', 'SY95-71', and 'Avocet S' (AvS) were used as susceptible controls in seedling and adult-plant tests throughout the study. The Pst races were kindly provided by the Plant Protection Institute of the Gansu Academy of Agricultural Sciences, Gansu, China.

\section{Evaluation of resistance to stripe rust}

Seedling tests to evaluate the stripe rust resistance of GX and TC 29 were conducted in a greenhouse using two prevalent Chinese Pst races (CYR32 and CYR34). Five plants of each line were sown in a plastic pot filled with nutrient soil and grown in a controlled environment in the greenhouse. Seedlings were inoculated at the two-leaf stage with each Pst race in accordance with the protocol of Hickey et al. (2012). Inoculated plants were placed in a dew chamber at $10{ }^{\circ} \mathrm{C}$ and $100 \%$ relative humidity for $24 \mathrm{~h}$ in the dark, and then moved to separate growth chambers at $15-16^{\circ} \mathrm{C}$ with $12-14 \mathrm{~h}$ of light daily. When the susceptible check 'Mingxian 169' showed full sporulation, the infection type (IT) on the second leaf

Page $4 / 20$ 
(approximately 15-18 days after inoculation) was scored using a 0-9 scale (Line and Qayoum 1992). Plants with IT scores of 0 to 6 were considered resistant, whereas plants with IT scores of 7 to 9 were considered susceptible.

Assessments of adult-plant stripe rust responses were conducted at the Chongzhou Experimental Station ( $30^{\circ} 33^{\prime} \mathrm{N}$, $\left.103^{\circ} 39^{\prime} E\right)$, Sichuan Agricultural University, Chengdu, China. The $F_{6: 8}$ RIL population and the parental lines were evaluated for APR to stripe rust during the 2017-2018, 2018-2019, and 2019-2020 growing seasons (referred to as CZ2018, CZ2019, and CZ2020, respectively). The NIL-derived population $\left(F_{2}\right)$ was evaluated for APR to stripe rust during the 2020-2021. In all tests, 20 seeds of each line were planted in rows $2 \mathrm{~m}$ in length and spaced $30 \mathrm{~cm}$ apart, with individual plants spaced $10 \mathrm{~cm}$ apart. The susceptible cultivar TC 29 was planted in every 20th row as a susceptible control. To provide inoculum for infection, the susceptible cultivars SY95-71 and AvS were planted around the perimeter of the experimental area as spreaders. Artificial inoculation was conducted using a mixture of currently predominant Pst races in China (comprising CYR32, CYR33, CYR34, G22-14, Su11-4, Su11-5, and Su11-7). Stripe rust response was first recorded by scoring the IT and disease severity (DS) when the susceptible checks SY95-71 and AvS showed more than 80\% DS, and was followed by two additional evaluations at 7-day intervals (i.e., three evaluations in total) for three randomly selected individual plants. The IT was recorded based on the 0-9 scale of Line and Qayoum (1992). The DS was scored as the percentage infected leaf area $(0,5 \%, 10 \%, 20 \%, 40 \%, 60 \%, 80 \%$, or $100 \%)$ in accordance with the Chinese National Standard, GB/T 15797-2011. The final DS (FDS) was used for phenotypic analysis.

\section{Genotyping, linkage map construction, and QTL analysis}

Genomic DNA was extracted from a single plant for each line of the wheat materials using the cetyltrimethylammonium bromide method (Stewart and Via 1993). The two parents (GX and TC 29) and the 117 RILs were genotyped using the Axiom ${ }^{\circledR}$ Wheat 55K SNP array (53,036 markers) by the China Golden Marker Biotechnology Company Ltd (Beijing, China). Monomorphic and SNP loci with a minor allele frequency less than 0.3 were excluded from further analysis (Ma et al. 2019). Polymorphic SNP markers were used to remove redundant markers in the binning step using the BIN function, with the parameters missing rate $=20 \%$ and distortion value $=0.01$, implemented in QTL IciMapping v4.2 (Wang et al. 2019b). The binned markers were used for linkage map construction using the Kosambi mapping function (Kosambi 1944) with JoinMap v4.0 (Van Ooijen 2006). Mapping of QTL was performed using QTL IciMapping v4.2 based on inclusive composite interval mapping with the preset parameters Step $=1 \mathrm{cM}, p$-value for entering variables $(\mathrm{PIN})=0.001$, and logarithm of the odds $(\mathrm{LOD})=2.5$.

\section{Haplotype analysis}

Haplotype analysis was performed to identify haplotype variants for QYr.GX-2AS in a collection of 325 Chinese wheat landrace accessions (Zhou et al. 2017; Ye et al. 2019). The informative markers linked to QYr.GX-2AS were screened using the Wheat $55 \mathrm{~K}$ or Wheat $660 \mathrm{~K}$ SNP arrays in accordance with the method described by Long et al. (2021). The SNP genotype data and the phenotype data (FDS) were obtained from recently published studies (Cheng et al. 2019; Long et al. 2019; Yao et al. 2019, 2020; Ye et al. 2019; Wang et al. 2021). Haplotype variants were detected using Haploview v4.2

(http://www.broad.mit.edu/mpg/haploview/). The haplotypes detected in at least 10 accessions were considered to be major haplotypes. Boxplots were generated to display the average FDS of accessions carrying the different haplotypes. Haplotype data were combined with provenance information to examine the geographic distribution of the superior haplotypes in the 10 major agro-ecological production zones of Chinese wheat landraces.

\section{Exome capture sequencing, development of KASP markers, and genetic mapping}


Genomic DNA of the parents, GX and TC 29, was sequenced using the wheat exome capture sequencing protocol described by Dong et al. (2020). The sequence variants were identified using the variant calling pipeline GATK4 (Heldenbrand et al. 2019). The SNPs in the target region for QYr.GX-2AS detected by exome capture sequencing and the Wheat $55 \mathrm{~K}$ array were converted to KASP markers using the PolyMarker online tool (Ramirez-Gonzalez et al. 2015). The KASP markers were used to screen the parents and NILs to confirm polymorphism before genotyping the NIL-derived population. The KASP assays were performed in 96-well format as $10 \mu \mathrm{L}$ reactions containing $2 \mu \mathrm{L}$ of 50-100 ng genomic DNA, $5 \mu \mathrm{L}$ of HiGeno $2 \times$ Probe Mix B, $0.24 \mu \mathrm{M}$ of each forward primer, $0.6 \mu \mathrm{M}$ of the common reverse primer, and double distilled water to make up the volume to $10 \mu \mathrm{L}$. Each PCR was conducted using the BIO-RAD CFX96 qPCR system. Thermocycling was performed with a touchdown protocol: $95^{\circ} \mathrm{C}$ for $10 \mathrm{~min} ; 95^{\circ} \mathrm{C}$ for $20 \mathrm{~s}$ and $61^{\circ} \mathrm{C}\left(-0.6{ }^{\circ} \mathrm{C}\right.$ per cycle) for $40 \mathrm{~s}$ for 10 cycles; and $95^{\circ} \mathrm{C}$ for $20 \mathrm{~s}$ and $55^{\circ} \mathrm{C}$ for $40 \mathrm{~s}$ for 38 cycles. Data analysis was performed manually using BIO-RAD CFX96 Manager 3.1.

Polymorphic KASP markers were genotyped in the NIL-derived population of 130 individuals $\left(\mathrm{F}_{2}\right)$ for validation of $Q Y$ r.GX2AS. Linkage analysis was performed using JoinMap v4.0 (Kyazma BV, Wageningen, The Netherlands) (Van Ooijen 2006) with a LOD threshold of 3.0. The Kosambi map function (Kosambi 1944) was used to convert the recombination fractions to centi-Morgans. The linkage map was drawn using Mapdraw v2.1 (Liu and Meng 2003). In addition, to check the usefulness of the newly developed KASP markers for marker-assisted selection, three tightly linked markers for QYr.GX-2AS were further assessed in 109 wheat cultivars grown in Sichuan.

\section{Data analyses}

Best linear unbiased prediction (BLUP) values for each RIL, analysis of variance (ANOVA), Pearson's correlation coefficients, and broad-sense heritability $\left(H^{2}\right)$ estimates were calculated using the "AOV" tool implemented in QTL IciMapping v4.2 (http://www.isbreeding.net) (Wang et al. 2019b). The goodness-of-fit of the observed rust response with the theoretical 3:1 ratio in the NIL-derived population $\left(F_{2}\right)$ was performed using the chi-square $\left(\chi^{2}\right)$ test with Excel 2016 (Microsoft, Redmond, WA, USA). Student's $t$-tests $(P<0.05$ and 0.01$)$ were conducted with SPSS Statistics v17.0 (IBM Corp., Armonk, NY, USA) to evaluate the significance of differences between the two groups.

\section{Results}

\section{Stripe rust response of the parents and RILs}

Plants of GX were susceptible (IT = 8) to CYR32 and CYR34 at the seedling stage (Fig. 1a), but exhibited strong resistance (IT $=3$, FDS < 10\%) to mixed Pst races at the adult-plant stage in three crop seasons from 2018 to 2020 (Fig. 1b, Fig. 2, Table S1). These results indicated that GX showed non-race-specific APR to stripe rust. The frequency distributions of RILs for FDS were continuous with a pronounced skewness towards resistance, and the average FDS of RILs for GX $\times$ TC 29 was $12.5 \%-$ $15.7 \%$ in the field tests, suggesting the presence of a large-effect QTL in the RIL population (Fig. 1C, Fig. 2, Table S1). Broadsense heritability $\left(H^{2}\right)$ was $96.7 \%$ for FDS in all tests (Table 1$)$. Correlation coefficients $\left(R^{2}\right)$ for FDS of the RILs among the different environments were significant $(P<0.01)$ and ranged from 0.82 to 0.95 (Table S2).

\section{Table 1}

The summary of final disease severity (FDS) data for the RILs population from the Gaoxianguangtoumai (GX) $\times$ Taichung 29 (TC 29) recorded in fields at Chongzhou in 2018-2020 


\begin{tabular}{lllllllll} 
Environments & \multicolumn{2}{l}{ Parents } & \multicolumn{2}{l}{ RIL population } & & & \\
& GX & TC 29 & Min-max & Mean & SD & CV & $H^{2}(\%)$ \\
\hline CZ2018 (\%) & 5.0 & 80.0 & $0-100$ & 14.0 & 25.2 & 1.8 & \\
\hline CZ2019 (\%) & 6.7 & 80.0 & $0-100$ & 12.5 & 23.7 & 1.9 & \\
\hline CZ2020 (\%) & 5.0 & 80.0 & $0-100$ & 15.7 & 27.0 & 1.7 & \\
\hline BLUP (\%) & 7.1 & 73.2 & $2.1-91.0$ & 14.6 & 21.2 & 1.5 & 96.7 \\
\hline
\end{tabular}

$\mathrm{SD}$,standard deviation; $\mathrm{CV}$,coefficient of variation; $H^{2}$, broad-sense heritability

\section{Linkage map construction and QTL analysis}

A total of 1,871 bin markers were used to construct the linkage map for the GX $\times$ TC 29 population (Table S3). The total length of the map covered 2,799.12 cM with an average interval of $1.50 \mathrm{cM}$ between adjacent markers and spanned 911.04 , 855.71 , and $1,032.37 \mathrm{cM}$ in the $\mathrm{A}, \mathrm{B}$, and $\mathrm{D}$ genomes, with a density of $1.34,1.28$, and $1.98 \mathrm{cM}$ per marker, respectively (Table S3). The map consisted of 21 linkage groups defined with representatives from each of the 21 chromosomes.

Two major QTL conferring APR to stripe rust were detected from the resistant parent GX in each of the three field tests and BLUP data (Table 2, Fig. 3a, b). The most highly significant QTL, designated QYr.GX-2AS, was mapped to the short arm of chromosome $2 \mathrm{AS}$ and explained up to $27.0 \%$ of the phenotypic variation with a LOD score of 8.1 (Table 2, Fig. 3a). A second QTL, QYr.GX-7DS, was flanked by the SNP markers AX-109379249 and AX-110431109 on chromosome 7DS and overlapped with Yr18, and explained $9.6 \%-15.6 \%$ of the phenotypic variation in all trials and BLUP data (Table 2, Fig. 3b). We concluded that it was highly likely that QYr.GX-7DS corresponded to Yr18.

To determine the effects of the QTL, the RILs were divided into four groups based on the presence/absence of the most closely linked flanking markers of QYr.GX-2AS and QYr.GX-7DS. Clearly, the RILs that carried one of the QTL showed a lower FDS than those without any QTL (average FDS $=63.4 \%$ ). In particular, the RILs carrying only QYr.GX-2AS showed only $9.3 \%$ of the average FDS, which was similar to the effect of both QTL in combination (average FDS $=7.1 \%$ ) (Fig. $3 \mathrm{c}$ ). This result indicated that $Q Y$ r.GX-2AS had a large effect on stripe rust resistance and provided relatively stronger resistance than QYr.GX-7DS.

\section{Table 2}

\section{Quantitative trait loci (QTL) for stripe rust resistance detected in the RILs population from the Gaoxianguangtoumai (GX) $\times$ Taichung 29 (TC 29) using final disease severity (FDS) data across three environments and BLUP values}




\begin{tabular}{|c|c|c|c|c|c|c|c|c|c|}
\hline QTL & Environment & Trait & Chromosome & LeftMarker & RightMarker & $\begin{array}{l}\text { Distance } \\
\text { (cM) }\end{array}$ & LOD & $\begin{array}{l}\text { PVE } \\
(\%)\end{array}$ & $\begin{array}{l}\text { Resistance } \\
\text { source }\end{array}$ \\
\hline \multirow[t]{4}{*}{$\begin{array}{l}Q Y{ }_{r} G X- \\
2 A S\end{array}$} & CZ2018 & FDS & $2 A S$ & $\begin{array}{l}A X- \\
109957471\end{array}$ & $\begin{array}{l}A X- \\
110026721\end{array}$ & 0.2 & 8.1 & 27.0 & GX \\
\hline & CZ2019 & & & $\begin{array}{l}A X- \\
109957471\end{array}$ & $\begin{array}{l}A X- \\
110026721\end{array}$ & 0.2 & 7.1 & 17.1 & \\
\hline & CZ2020 & & & $\begin{array}{l}A X- \\
109957471\end{array}$ & $\begin{array}{l}A X- \\
110026721\end{array}$ & 0.2 & 5.2 & 15.5 & \\
\hline & BLUP & & & $\begin{array}{l}A X- \\
109957471\end{array}$ & $\begin{array}{l}A X- \\
110026721\end{array}$ & 0.2 & 7.7 & 21.8 & \\
\hline \multirow[t]{4}{*}{$\begin{array}{l}\text { QYr.GX- } \\
7 D S\end{array}$} & CZ2018 & FDS & 7DS & $\begin{array}{l}A X- \\
109379249\end{array}$ & $\begin{array}{l}A X- \\
89737284\end{array}$ & 9.6 & 3.3 & 9.6 & GX \\
\hline & CZ2019 & & & $\begin{array}{l}A X- \\
110502471\end{array}$ & $\begin{array}{l}A X- \\
109303704\end{array}$ & 9.6 & 6.6 & 15.6 & \\
\hline & CZ2020 & & & $\begin{array}{l}A X- \\
109303704\end{array}$ & $\begin{array}{l}A X- \\
110431109\end{array}$ & 9.6 & 4.9 & 13.6 & \\
\hline & BLUP & & & $\begin{array}{l}A X- \\
89737284\end{array}$ & $\begin{array}{l}A X- \\
89378255\end{array}$ & 9.6 & 4.4 & 10.9 & \\
\hline
\end{tabular}

\section{Haplotype analysis of QYr.GX-2AS}

To assess the distribution of QYr.GX-2AS among 325 Chinese wheat landraces, the favorable haplotype was identified by haplotype analysis and seven SNP markers tightly linked to QYr.GX-2AS were screened from the Wheat $55 \mathrm{~K}$ or $660 \mathrm{~K} \mathrm{SNP}$ arrays (Fig. 4a, b, C). Eight major haplotypes ( $n>10$ ) were detected in the panel (Fig. 4a, b). GX and 15 other accessions clustered with Hap1 (Table S4), which showed a frequency of about 5.3\% in the total population (Fig. 4a). Almost all accessions carrying Hap1, except one from Henan, were collected from Sichuan. The accessions carrying Hap1 showed $18.4 \%$ of the average FDS and thus were more strongly resistant to stripe rust than those accessions carrying other haplotypes ( Hap2 $=37.2 \%$, Hap3 $=24.1 \%$, Hap4 $=47.7 \%$, Hap5 $=21.5 \%$, Hap6 $=39.0 \%$, Hap7 $=27.0 \%$, Hap8 $=47.6 \%)($ Fig. 4c). These results revealed that the favorable haplotype of QYr.GX-2AS was Hap1, which was relatively rare among the Chinese wheat landraces.

\section{Validation and mapping of QYr.GX-2AS}

To further validate and map the location of QYr.GX-2AS, the SNPs in the target region for QYr.GX-2AS identified by exome capture sequencing and the Wheat $55 \mathrm{~K}$ array were selected for conversion to KASP markers. Eleven markers were confirmed to be polymorphic between GX and TC 29 (Table S5). Combined with the KASP markers for QYr.GX-2AS, a NIL-derived population of 130 individuals $\left(F_{2}\right)$ for QYr.GX-2AS was developed from a residual heterozygous plant in the $F_{8}$ generation of RILs. No significant phenotypic differences were observed in the NIL-derived population, except for APR to stripe rust (Fig. $5 a)$. With regard to stripe rust response in the field test, the $F_{2}$ plants of the NIL-derived population were clearly classifiable into 97 resistant ( $I T \leq 6)$ and 33 susceptible ( $I T \geq 7$ ) individuals, which fits the expected ratio (3:1) for a single Mendelian factor (chi-square goodness-of-fit test, $\chi^{2}=0.01, P=0.92$ ) (Table $S 6$ ). Using the newly developed eleven KASP markers (Table S6) to construct the genetic map, QYr.GX-2AS was localized to a $1.37 \mathrm{Mb}$ interval between KP2A_36.85 and KP2A_38.22, and co-segregated with the KASP marker KP2A_37.09 (Fig. 5b).

\section{Validation of KASP markers for marker-assisted selection}


To check the specificity and polymorphism of the linked marker of QYr.GX-2AS for marker-assisted selection, a set of 109 Chinese wheat cultivars was tested with the markers KP2A_36.85, KP2A_37.09, and KP2A_38.22 (Fig. S1, Table S7). Most of the lines amplified the susceptible-specific alleles in the three markers, which showed $85.3 \%, 99.1 \%$, and $95.4 \%$ polymorphism, respectively, in the cultivars (Table S7). Thus, these KASP markers can be used as the specificity markers for marker-assisted selection of QYr.GX-2AS in the vast majority of Chinese wheat cultivars.

\section{Discussion}

Breeding for durable resistance to stripe rust has been among the highest priorities for wheat breeding in the last decade (Chen 2013). A large number of genes or QTL that confer various degrees of APR to stripe rust have been identified, but most only have minor effects on stripe rust response and are therefore difficult to use in breeding. Thus, identification of genes or QTL with a high degree of APR that are useful in breeding programs is required. The Chinese wheat landrace GX has displayed a high degree of APR to stripe rust in field environments for more than a decade in southwest China. The strong APR to stripe rust of GX is conferred by two QTL identified on chromosomes 2AS and 7DS, respectively. The QTL on 2AS (QYr.GX-2AS), being more effective than the QTL on 7DS (Yr18), had a large effect in the reduction of stripe rust severity at adult-plant stages, and thus shows great potential for use in breeding durable resistance to stripe rust in wheat.

QTL analysis is a useful procedure to reveal possible multiple loci when analyzing complex genetic traits, such as APR to stripe rust, in resistant germplasm. However, this procedure only allows approximate mapping of the QTL (Tanksley and Hewitt 1988) owing to the heterogeneity in genetic backgrounds. The confidence interval of many QTL spans a considerable genetic distance and, as a result, molecular markers for these QTL may not be reliably used in marker-assisted selection. As a strategy for accurate mapping of QTL in genetic analysis, NIL-derived populations that allow the conversion of a quantitative trait into a Mendelian factor have been widely used for fine mapping and cloning of many important QTL in wheat, such as Yr18 (Krattinger et al. 2009), Yr36 (Fu et al. 2009), Fhb1 (Su et al. 2019), and Fhb7 (Wang et al. 2020). In the present research, a NIL-derived population targeting QYr.GX-2AS was developed based on the method of heterogeneous inbred family analysis (Tuinstra et al. 1997). Members of this population were unambiguously classified as either resistant or susceptible and fitted the expected ratio (3:1) for a single Mendelian factor; thus, accurate mapping of the locus was possible. Analysis of the NIL population revealed that QYr.GX-2AS, flanked by KP2A_36.85 and KP2A_38.22, was located in the interval $36.85 \mathrm{Mb}$ to 38.22 $\mathrm{Mb}$ on chromosome $2 \mathrm{AS}$. One KASP marker co-segregating with the targeted locus was successfully developed for markerassisted selection.

Several genes that confer resistance to stripe rust have been identified on wheat chromosome 2AS, including Yr17 (Bariana and Mcintosh 1993), Yr56 (McIntosh et al. 2014), Yr69 (Hou et al. 2016), YrR61 (Hao et al. 2011), and YrSph (Chen et al. 2012) (Fig. 6, Table S8). The genes Yr17, Yr69, and YrSph confer ASR to stripe rust. Although recent studies suggest that Yr17 also confers APR to stripe rust in the field, QYr.GX-2AS is likely to differ from Yr17 because accessions of the Chinese wheat landrace $\mathrm{GX}$ that lack the $2 \mathrm{~N}$ alien segment carry Yr17. Yr56 is a major gene conferring APR to stripe rust that was identified in the Australian durum wheat cultivar 'Wollaroi'. Yr56 is flanked by Xsun167 (wPt-4197) and Xsun168 (wPt-9104) (Mclntosh et al. 2014), which corresponds to the 'Chinese Spring' physical map region between $8.35 \mathrm{Mb}$ and 14.28 Mb. YrR61, corresponding to the major-effect QTL QYr.uga-2AS_26R61 conferring APR to stripe rust, was identified from the soft red winter wheat cultivar 'Pioneer' and is flanked by the markers Xbarc124 (3.78 Mb) and Xgwm359 (28.20 Mb) (Hao et al. 2011). Clearly, both Yr56 and YrR61 are located distant from QYr.GX-2AS. In addition, at least 20 QTL have been reported on chromosome 2AS, and most of them are located at a QTL hot-spot region in the distal end of 2AS (<30 Mb) (Fig. 6). For example, QYr.ufs-2A (Agenbag et al. 2012), QYrst.orr-2AS_Stephens (Vazquez et al. 2012) and QYr.sun-2A_Kukri (Bariana et al. 2010) were all flanked by the basis of a common DArT marker XwPt-0003, which were nearly with the QYrva.vt2AS_VAOOW-38 (Christopher et al. 2013) corresponds to the 'Chinese Spring' physical map region $29.94 \mathrm{Mb}$. QYrtb.orz-2AS (Vazquez et al. 2015) and QYr.inra_2AS.1_Recital (Dedryver et al. 2009) were located in 2AS close to marker Xcfd36 (about $16.63 \mathrm{Mb}$ ) which are homeologous to the Yr17 introgression. The QYr.ucw-2AS_PI610750 (Lowe et al. 2011), contributed by the synthetic derivative PI610750, is flanked by the XWPt-3896 (13.14 Mb) and Xwmc177(33.70 Mb). QYr.inra- 
2A_CampRemy from Camp Remy (Mallard et al. 2005) is located by the Xgwm382a and Xgwm359 (about $28.20 \mathrm{Mb}$ ). QYrzv.swust-2AS (Zhou et al. 2021) flanked by IWB7877 and IWB72720 is derived from the wild emmer wheat ( $T$.

dicoccoides) accession Zavitan, corresponding to the 'Chinese Spring' physical map region between $5.25 \mathrm{Mb}$ and $5.33 \mathrm{Mb}$. Similarly, the other QTL identified by GWAS are located in different regions from QYr.GX-2AS on chromosome 2AS, expect for a minor locus QYr.wsu-2A.1_IWA2526 (about $36.63 \mathrm{Mb}$ ). Hence, the large-effect QTL QYr.GX-2AS identified in the present study is unlikely to be the previously reported QTL.

According to gene annotation information in IWGSC RefSeq v1.1, 16 predicted genes are located in the candidate region for QYr.GX-2AS (Fig. 5c, Table S9). None of these genes is a classic NBS-LRR resistance gene. In addition, no annotations accorded with the protein types encoded by the APR genes Yr18 (ABC transporter), Yr36 (kinase-START), and Yr48 (hexose transporter), implying that the candidate gene for QYr.GX-2AS might differ from known stripe rust resistance genes. Combined with exon sequencing data, eight predicted genes showed non-synonymous variants between GX and 'Chinese Spring' in exon regions, including a RING/U-box, ascorbate peroxidase, glycosyltransferases, and F-box family protein, that may be involved in disease resistance. For confirmation of the candidate gene and cloning of QYr.GX-2AS, fine mapping to narrow the candidate interval will be performed using a large NIL-derived population in future work.

\section{Declarations}

\section{Funding}

We acknowledge financial support from the National Key Research and Development Program of China (2016YFD0100100), the International Science and Technology Cooperation and Exchanges Programs of Science and Technology Department of Sichuan Province (2019YFH0063) and the Applied Basic Research Programs of Sichuan Province (2021YJ0297).

\section{Conflicts of interest}

The authors declare that they have no competing interests.

\section{Availability of data and material}

The datasets supporting the conclusions of this study are included in this article and its supplementary information files. The raw sequence data have been submitted to GenBank under Bioproject no. PRJNA734801. The materials, including the resistant Chinese wheat landrace 'Gaoxiangguangtoumai' (GX), used in this study are deposited at Triticeae Research Institute, Sichuan Agricultural University and National Germplasm Bank, China (NGBC).

\section{Code availability}

Not applicable.

\section{Authors' contributions}

YQW and FYL carried out the experiment, analyzed the data, and drafted the manuscript; FNG, FJY, LL, XYZ, LYD, YW and HL carried out the phenotypic evaluation; WL, QTJ, YMW, JM, PFQ, MD and YLZ provided resources and technique guidance; HYK, YFJ and GYC designed and carried out the experiment, formulated the questions, analysed the data and revised the manuscript. All authors have reviewed and approved the final manuscript.

\section{References}

Page $10 / 20$ 
1. Agenbag GM, Pretorius ZA, Boyd LA, Bender CM, Prins R (2012) Identification of adult plant resistance to stripe rust in the wheat cultivar cappelle-desprez. Theor Appl Genet 125:109-120

2. Bansal UK, Hayden MJ, Keller B, Wellings CR, Bariana HS (2010) Relationship between wheat rust resistance genes Yr1 and Sr48 and a microsatellite marker. Plant Pathol 58:1039-1043

3. Bariana HS, Mclntosh RA (1993) Cytogenetic studies in wheat. XV. Location of rust resistance genes in VPM1 and their genetic linkage with other disease resistance genes in chromosome 2A. Genome 36:476-482

4. Bariana HS, Bansal UK, Schmidt A, Lehmensiek A, Kaur J, Miah H, Howes N, Mclntyre CL (2010) Molecular mapping of adult plant stripe rust resistance in wheat and identification of pyramided QTL genotypes. Euphytica 176:251-260

5. Basnet BR, Ibrahim AMH, Chen XM et al (2014) Molecular mapping of stripe rust resistance in hard red winter wheat TAM 111 adapted to the U.S. high plains. Crop Sci 54:1361-1373

6. Cao J, Xu Z, Fan X, Zhou Q, Ji G, Wang F, Feng B, Wang T (2020) Genetic mapping and utilization analysis of stripe rust resistance genes in a Tibetan wheat (Triticum aestivum L.) landrace Qubaichun. Genet Resour Crop Ev 67:1765-1775

7. Chen SS, Chen GY, Chen H, Wei YM, Li W, Liu YX, Liu DC, Lan XJ, Zheng YL (2012) Mapping stripe rust resistance gene YrSph derived from Tritium sphaerococcum Perc. with SSR, SRAP, and TRAP markers. Euphytica 185:19-26

8. Chen WQ, Wellings C, Chen XM, Kang ZS, Liu TG (2014) Wheat stripe (yellow) rust caused by Puccinia striiformis $\mathrm{f}$. Sp. Tritici. Mol Plant Pathol 15:433-446

9. Chen XM (2013) High-temperature adult-plant resistance, key for sustainable control of stripe rust. Am J Plant Sci 4:608-627

10. Chen XM, Kang ZS (2017) Stripe rust. Springer Netherlands, pp 353-618

11. Cheng P, Xu LS, Wang MN, See DR, Chen XM (2014) Molecular mapping of genes Yr64 and Yr65 for stripe rust resistance in hexaploid derivatives of durum wheat accessions PI 331260 and PI 480016. Theor Appl Genet 127:2267-2277

12. Cheng YK, Li J, Yao FJ, Long L, Wang YQ, Wu Y, Li J, Ye XL, Wang JR, Jiang QT, Kang HY, Li W, Qi PF, Liu YX, Deng M, Ma J, Jiang YF, Chen XM, Zheng YL, Wei YM, Chen GY (2019) Dissection of loci conferring resistance to stripe rust in Chinese wheat landraces from the middle and lower reaches of the Yangtze River via genome-wide association study. Plant Sci 287:110204

13. Christopher MD, Liu S, Hall MD, Marshall DS, Griffey CA (2013) Identification and mapping of adult plant stripe rust resistance in soft red winter wheat VA00W-38. Plant Breeding 132:53-60

14. Dedryver F, Paillard S, Mallard S, Robert O, Trottet M, Nègre S, Verplancke G, Jahier J (2009) Characterization of genetic components involved in durable resistance to stripe rust in the bread wheat "Renan". Phytopathology 99:968-973

15. Dong CH, Zhang LC, Chen ZX, Xia C, Gu YQ, Wang JR, Li DP, Xie ZC, Zhang Q, Zhang XY, Gui LX, Liu X, Kong XY (2020) Combining a new exome capture panel with an effective varBScore algorithm accelerates BSA-based gene cloning in Wheat. Front Plant Sci https://. doi:10.3389/fpls.2020.01249

16. Fu DL, Uauy C, Distelfeld A, Blechl A, Epstein L, Chen XM, Sela H, Fahima T, Dubcovsky J (2009) A kinase-START gene confers temperature-dependent resistance to wheat stripe rust. Science 323:1357-1360

17. Han DJ, Kang ZS (2018) Current status and future strategy in breeding wheat for resistance to stripe rust in China. Plant Protection 44:1-12

18. Hao Y, Chen Z, Wang Y, Bland D, Buck J, Brown-Guedira G, Johnson J (2011) Characterization of a major QTL for adult plant resistance to stripe rust in US soft red winter wheat. Theor Appl Genet 123:1401-1411

19. Heldenbrand JR, Baheti S, Bockol MA, Drucker TM, Hart SN, Hudson ME, lyer RK, Kalmbach MT, Kendig KI, Klee EW, Mattson NR, Wieben ED, Wiepert M, Wildman DE, Mainzer LS (2019) Recommendations for performance optimizations when using GATK3.8 and GATK4. BMC Bioinformatics 20:557

20. Hickey L, Wilkinson PM, Knight CR, Godwin ID, Kravchuk OY, Aitken EAB, Bansal UK, Bariana HS, Delacy IH, Dieters MJ (2012) Rapid phenotyping for adult-plant resistance to stripe rust in wheat. Plant Breeding 131:54-61 
21. Hou LY, Jia JQ, Zhang XJ, Li X, Yang ZJ, Ma J, Guo HJ, Zhan HX, Qian LY, Chang ZJ (2016) Molecular mapping of the stripe rust resistance gene Yr69 on wheat chromosome 2AS. Plant Dis 100:1717-1724

22. Klymiuk V, Yaniv E, Huang L et al (2018) Cloning of the wheat Yr15 resistance gene sheds light on the plant tandem kinase-pseudokinase family. Nat Commun 9:3735

23. Knott DR (1989) The mode of inheritance of a type of dwarfism in common wheat. Genome 32:932-933

24. Kosambi DD (1944) The estimation of map distances from recombination values. Ann Eugen 12:172-175

25. Krattinger SG, Lagudah ES, Spielmeyer W, Singh RP, Huerta-Espino J, McFadden H, Bossolini E, Selter LL, Keller B (2009) A putative $A B C$ transporter confers durable resistance to multiple fungal pathogens in wheat. Science 323:1360-1363

26. Lan CX, Liang SS, Zhou XC, Zhou G, Lu QL, Xia XC, He ZH (2010) Identification of genomic regions controlling adult-plant stripe rust resistance in Chinese landrace Pingyuan 50 through bulked segregant analysis. Phytopathology 100:313-318

27. Li ZQ, Zeng SM (2000) 'Wheat rusts in China'. China Agricultural Press, China

28. Line RF, Qayoum A (1992) Virulence, aggressiveness, evolution, and distribution of races of Puccinia striiformis (the cause of stripe rust of wheat) in North America, 1968-1987. Department of Agriculture Technical Bulletin U.S. No. 1788. http://naldc.nal.usda.gov/download/CAT92983836/PDF

29. Liu B, Liu TG, Zhang ZY, Jia QZ, Wang BT, Gao L, Peng YL, Jin SL, Chen WQ (2017) Discovery and pathogenicity of CYR34, a new race of Puccinia striiformis f. sp. tritici in China. Acta Phytopathol Sin 47:681-687

30. Liu RH, Meng JL (2003) MapDraw: a microsoft excel macro for drawing genetic linkage maps based on given genetic linkage data. Hereditas 25:317-321

31. Long L, Yao FJ, Guan FN, Cheng YK, Duan LY, Zhao XY, Li H, Pu ZE, Li W, Jiang QT, Wei YM, Ma J, Kang HY, Dai SF, Qi PF, Xu Q, Deng M, Zheng YL, Jiang YF, Chen GY (2021) A stable QTL on chromosome 5BL combined with Yr18 conferring high-level adult-plant resistance to stripe rust in Chinese wheat landrace Anyuehong. Phytopathology https://doi: 10.1094/PHYTO-10-20-0465-R

32. Long L, Yao FJ, Yu C, Ye XL, Cheng YK, Wang YQ, Wu Y, Li J, Wang JR, Jiang QT, Li W, Ma J, Liu YX, Deng M, Wei YM, Zheng YL, Chen GY (2019) Genome-wide association study for adult-plant resistance to stripe rust in Chinese wheat landraces (Triticum aestivum L.) from the yellow and Huai river valleys. Front Plant Sci 10:596

33. Lowe I, Cantu D, Dubcovsky J (2011) Durable resistance to the wheat rusts: integrating systems biology and traditional phenotype-based research methods to guide the deployment of resistance genes. Euphytica 179:69-79

34. Ma DF, Li Q, Tang MS, Chao KX, Li JC, Wang BT, Jing JX (2015) Mapping of gene conferring adult plant resistance to stripe rust in Chinese wheat landrace Baidatou. Mol Breed 35:157

35. Ma J, Qin NN, Cai B, Chen GY, Ding PY, Zhang H, Yang CC, Huang L, Mu Y, Tang HP, Liu YX, Qi PF, Jiang QT, Zheng YL, Liu CJ, Lan XJ, Wei YM (2019) Identification and validation of a novel major QTL for all-stage stripe rust resistance on 1BL in the winter wheat line 20828. Theor Appl Genet 132:1363-1373

36. Mallard S, Gaudet D, Aldeia A, Abelard C, Besnard AL, Sourdille P, Dedryver F (2005) Genetic analysis of durable resistance to yellow rust in bread wheat. Theor Appl Genet 110:1401-1409

37. Manickavelu A, Joukhadar R, Jighly A, Lan CX, Huerta-Espino J, Stanikzai AS, Kilian A, Singh RP, Ban T (2016) Genome wide association mapping of stripe rust resistance in afghan wheat landraces. Plant Sci 252:222-229

38. Marchal C, Zhang J, Zhang P et al (2018) BED-domain-containing immune receptors confer diverse resistance spectra to yellow rust. Nat Plants 4:662-668

39. Mcintosh RA, Dubcovsky J, Rogers J, Morris C, Appels R, Xia XC (2014) Catalogue of gene symbols for wheat: 20132014 supplement. Komugi-wheat Genetic Resources Database,

http://shigen.nig.ac.jp/wheat/komugi/genes/macgene/supplement 2013.pdf 2014

40. McIntosh RA, Hart GE, Gale MD (2018) Catalog of gene symbols for wheat-1991 supplement. Cereal Res Commun 19:491-508 
41. Gessese M, Bariana H, Wong D, Hayden M, Bansal U (2019) Molecular mapping of stripe rust resistance gene Yr81 in a common wheat landrace Aus27430. Plant Dis 103:1166-1171

42. Moore JW, Herrera-Foessel S, Lan C, Schnippenkoetter W, Aylife M, Huerta-Espino J, Lillemo M, Viccars L, Milne R, Periyannan S, Kong X, Spielmeyer W, Talbot M, Bariana H, Patrick JW, Dodds P, Singh R, Lagudah E (2015) A recently evolved hexose transporter variant confers resistance to multiple pathogens in wheat. Nat Genet 47:1494-1498

43. Ramirez-Gonzalez RH, Uauy C, Caccamo M (2015) PolyMarker: a fast polyploid primer design pipeline. Bioinform 31:2038-2039

44. Rosewarne GM, Herrera-Foessel SA, Singh RP, Huerta-Espino J, Lan CX, He ZH (2013) Quantitative trait loci of stripe rust resistance in wheat. Theor Appl Genet 126:2427-2449

45. Sharma-Poudyal D, Chen XM, Wan AM, Zhan GM, Kang ZS, Cao SQ, Jin SL, Morgounov A, Akin B, Mert Z, Shah SJA, Bux H, Ashraf M, Sharma RC, Madariaga R, Puri KD, Wellings C, Xi KQ, Wanyera R, Manninger K, Ganzalez MI, Koyda M, Sanin S, Patzek LJ (2013) Virulence characterization of international collections of the wheat stripe rust pathogen, Puccinia striiformis f. sp. tritici. Plant Dis 97:379-386

46. Stewart CN, Via LE (1993) A rapid CTAB DNA isolation technique useful for RAPD fingerprinting and other PCR applications. Biotechniques 14:748-751

47. Su Z, Bernardo A, Tian B (2019) A deletion mutation in TaHRC confers Fhb1 resistance to Fusarium head blight in wheat. Nat Genet 51:1099-1105

48. Tanksley SD, Hewitt J (1988) Use of molecular markers in breeding for soluble solids content in tomato - a reexamination. Theor Appl Genet 75:811-823

49. Tuinstra MR, Ejeta G, Goldsbrough PB (1997) Heterogeneous inbred family (HIF) analysis: a method for developing near isogenic lines that diffffer at quantitative trait loci. Theor Appl Genet 95:1005-1011

50. Van Ooijen JW (2006) JoinMap® 4.0, Software for the calculation of genetic linkage maps in experimental populations Kyazma BV, Wageningen, The Netherlands

51. Vazquez MD, Peterson CJ, Riera-Lizarazu O, Chen X, Heesacker A, Mundt C (2012) Genetic analysis of adult plant, quantitative resistance to stripe rust in wheat cultivar 'Stephens' in multi-environment trials. Theor Appl Genet 124:1-11

52. Vazquez MD, Robert Z, Peterson CJ, Chen XM, Heesacker A, Mundt CC (2015) Multi-location wheat stripe rust qtI analysis: genetic background and epistatic interactions. Theor Appl Genet 128:1307-1318

53. Wan AM, Zhao ZH, Chen XM, He ZH, Jin SL, Jia QZ, Yao G, Yang JX, Wang BT, Li GB, Bi YQ, Yuan ZY (2004) Wheat stripe rust epidemic and virulence of Puccinia striiformis f. sp. tritici in China in 2002. Plant Dis 88:896-904

54. Wang H, Sun S, Ge W (2020) Horizontal gene transfer of Fhb7 from fungus underlies Fusarium head blight resistance in wheat. Science 368:eaba5435

55. Wang JK, Li HH, Zhang LY, Meng L (2019b) User's manual of QTL Ici-Mapping ver. Quantitative Genetics group, Institute of Crop Science, Chinese Academy of Agricultural Sciences CAAS/Genetic Resources Program, International Maize and Wheat Improvement Center CIMMYT, Beijing/Mexico City

56. Wang L, Zheng D, Zuo SX, Chen XM, Zhuang H, Huang LL, Kang ZS, Zhao J (2018) Inheritance and linkage of virulence genes in Chinese predominant race CYR32 of the wheat stripe rust pathogen Puccinia striiformis f. sp. tritici. Front Plant Sci 9:120

57. Wang YQ, Yu C, Cheng YK, Yao FJ, Long L, Wu Y, Li J, Li H, Wang JR, Jiang QT, Li W, Pu ZE, Qi PF, Ma J, Deng M, Wei YM, Chen XM, Chen GY, Kang HY, Jiang YF, Zheng YL (2021) Genome-wide association mapping reveals potential novel loci controlling stripe rust resistance in a Chinese wheat landrace diversity panel from the southern autumn-sown spring wheat zone. BMC Genom 22:1-15

58. Wang Z, Ren JD, Du ZY, Che MZ, Zhang YB, Quan W, Jiang X, Ma Y, Zhao Y, Zhang ZJ (2019a) Identification of a major QTL on chromosome arm 2AL for reducing yellow rust severity from a Chinese wheat landrace with evidence for durable resistance. Theor Appl Genet 132:457-471

Page 13/20 
59. Wellings CR (2011) Global status of stripe rust: A review of historical and current threats. Euphytica 179:129-141

60. Wu JH, Huang S, Zeng QD, Liu SJ, Wang QL, Mu JM, Yu SZ, Han DJ, Kang ZS (2018) Comparative genome-wide mapping versus extreme pool-genotyping and development of diagnostic SNP markers linked to QTL for adult plant resistance to stripe rust in common wheat. Theor Appl Genet 131:1777-1792

61. Wu XL, Wang JW, Cheng YK, Ye XL, Li W, Pu ZE, Jiang QT, Wei YM, Deng M, Zheng YL, Chen GY (2016) Inheritance and molecular mapping of an all-stage stripe rust resistance gene derived from the Chinese common wheat land race 'Yilongtuomai'. J Hered 107:463-470

62. Wu Y, Wang YQ, Yao FJ, Long L, Li J, Li H, Pu ZE, Li W, Jiang QT, Wang JR, Wei YM, Ma J, Kang HY, Qi PF, Dai SF, Deng M, Zheng YL, Jiang YF, Chen GY (2020) Molecular mapping of a novel QTL conferring adult plant resistance to stripe rust in Chinese wheat landrace 'Guangtoumai'. Plant Dis. https://doi.org/10.1094/PDIS-07-20-1544-RE

63. Xu LS, Wang MN, Cheng P, Kang ZS, Hulbert SH, Chen XM (2013) Molecular mapping of Yr53, a new gene for stripe rust resistance in durum wheat accession PI 480148 and its transfer to common wheat. Theor Appl Genet 26:523-533

64. Yao FJ, Long L, Wang YQ, Duan LY, Zhao XY, Jiang YF, Li H, Pu ZE, Li W, Jiang QT, Wang JR, Wei YM, Ma J, Kang HY, Dai SF, Qi PF, Zheng YL, Chen XM, Chen GY (2020) Population structure and genetic basis of the stripe rust resistance of 140 Chinese wheat landraces revealed by a genome-wide association study. Plant Sci 110688

65. Yao FJ, Zhang XM, Ye XL, Li J, Long L, Yu C, Li J, Wang YQ, Wu Y, Wang JR, Jiang QT, Li W, Ma J, Wei YM, Zheng YL, Chen GY (2019) Characterization of molecular diversity and genome-wide association study of stripe rust resistance at the adult plant stage in northern Chinese wheat landraces. BMC Genet 20:38

66. Ye XL, Li J, Cheng YK, Yao FJ, Long L, Yu C, Wang YQ, Wu Y, Li J, Wang JR, Jiang QT, Li W, Ma J, Wei YM, Zheng YL, Chen GY (2019) Genome-wide association study of resistance to stripe rust (puccinia striiformis f. sp. triticl) in sichuan wheat. BMC Plant Biol 19:147

67. Zeng SM, Luo Y (2006) Long-Distance spread and interregional epidemics of wheat stripe rust in china. Plant Dis 90:980-988

68. Zhang HY, Wang Z, Ren JD, Du ZY, Quan W, Zhang YB, Zhang ZJ (2017) A QTL with major effect on reducing stripe rust severity detected from a Chinese wheat landrace. Plant Dis 101:1533-1539

69. Zhou XL, Han DJ, Chen XM, Gou HL, Guo SJ, Rong L, Wang QL, Huang LL, Kang ZS (2014) Characterization and molecular mapping of stripe rust resistance gene Yr61 in winter wheat cultivar Pindong 34. Theor Appl Genet 27:23492358

70. Zhou XL, Zhong X, Roter J et al (2021) Genome-wide mapping of loci for adult-plant resistance to stripe rust in durum wheat Svevo using the 90K SNP array. Plant Dis 105:879-888

71. Zhou Y, Tang H, Cheng MP, Dankwa K, Chen ZX, Li ZY, Gao S, Liu YX, Jiang QT, Lan XJ, Pu ZE, Wei YM, Zheng YL, Hickey LT, Wang JR (2017) Genome-wide association study for pre-harvest sprouting resistance in a large germplasm collection of Chinese wheat landraces. Front Plant Sci 8:401-413

\section{Figures}




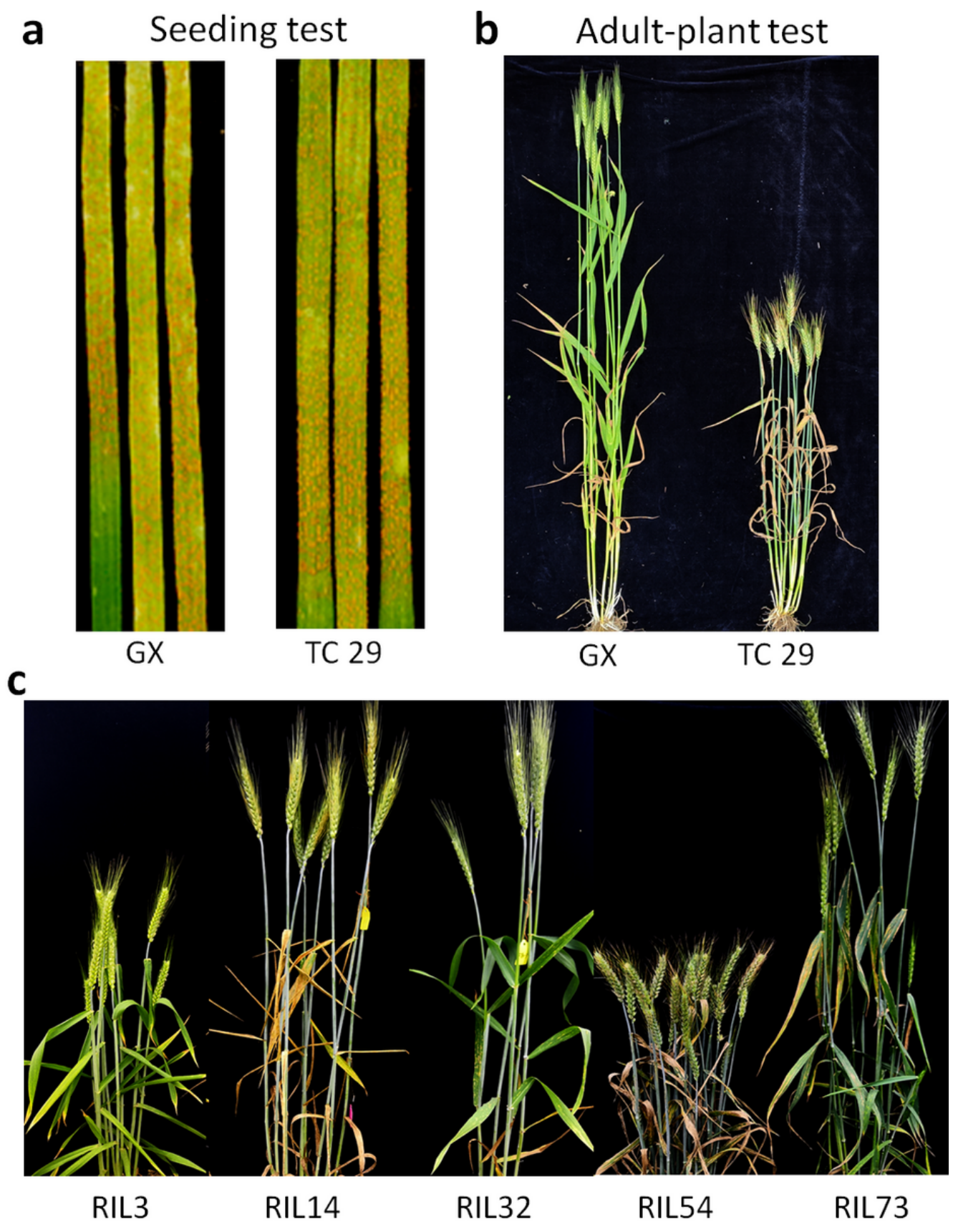

Figure 1

Stripe rust response of the resistant parent Gaoxianguangtoumai (GX) and susceptible parent Taichung 29 (TC 29) with CYR34 at the seedling stage (a) and mixture Pst at the adult-plant stage (b); Stripe rust response of the randomly selected RILs of lines in the field (c). 

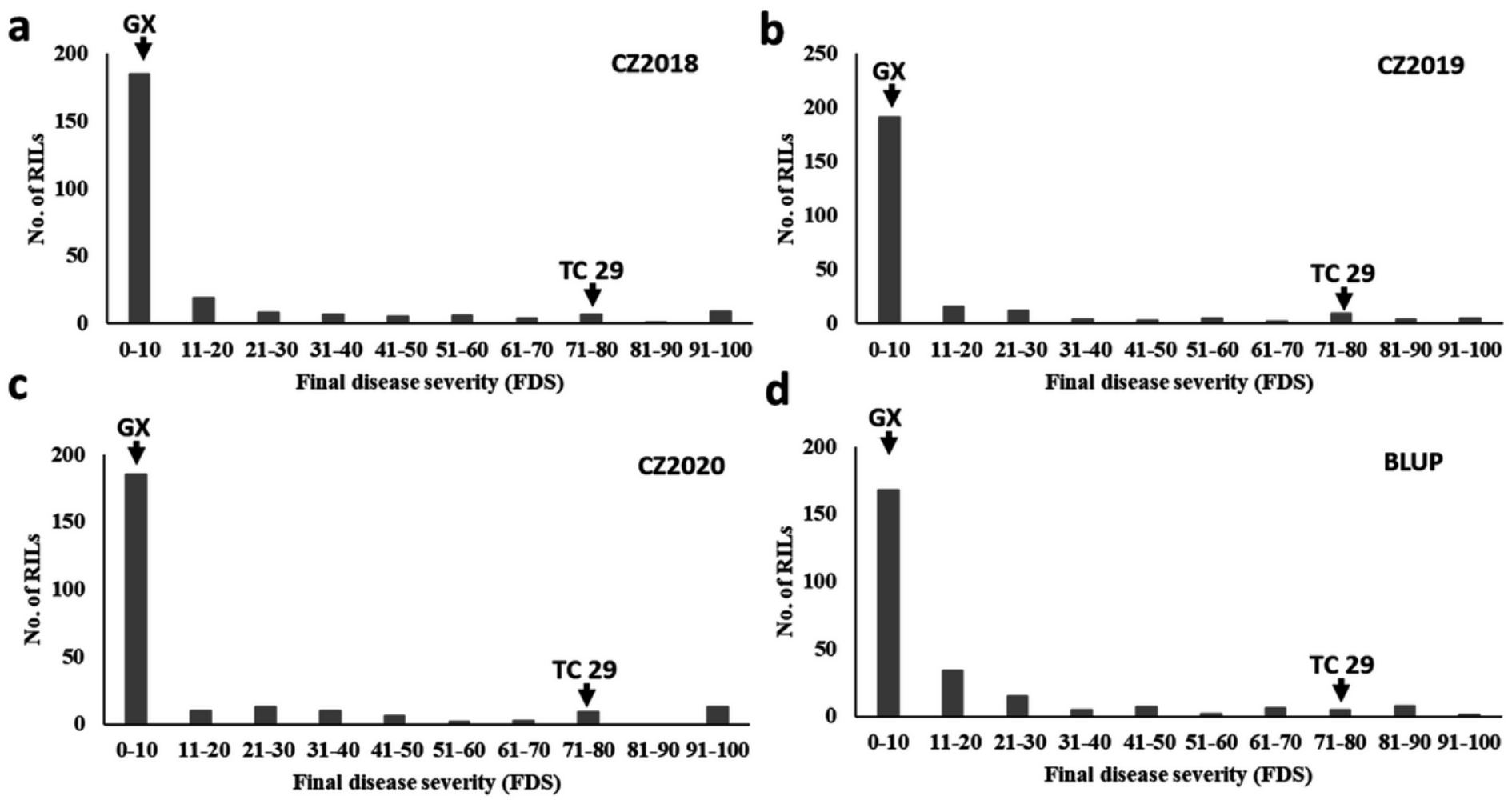

Figure 2

Frequency distributions of the final disease severity (FDS) for the RIL population derived from Gaoxianguangtoumai (GX) $\times$ Taichung 29 (TC 29) at Chongzhou in 2018 (a), 2019 (b), 2020 (c) and BLUP values (d). 
a

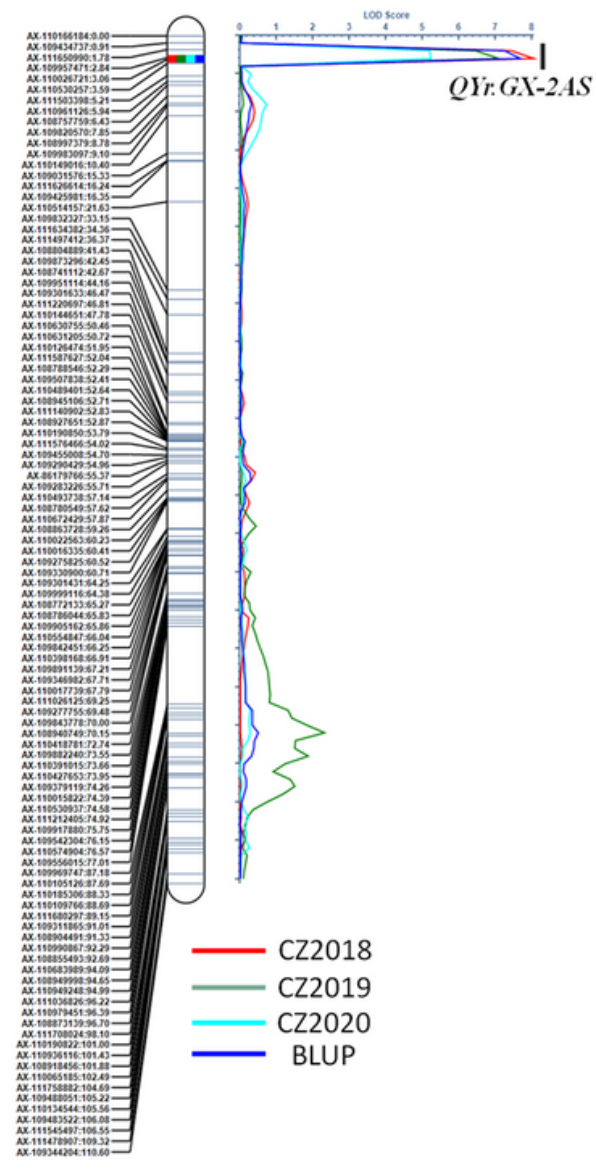

b

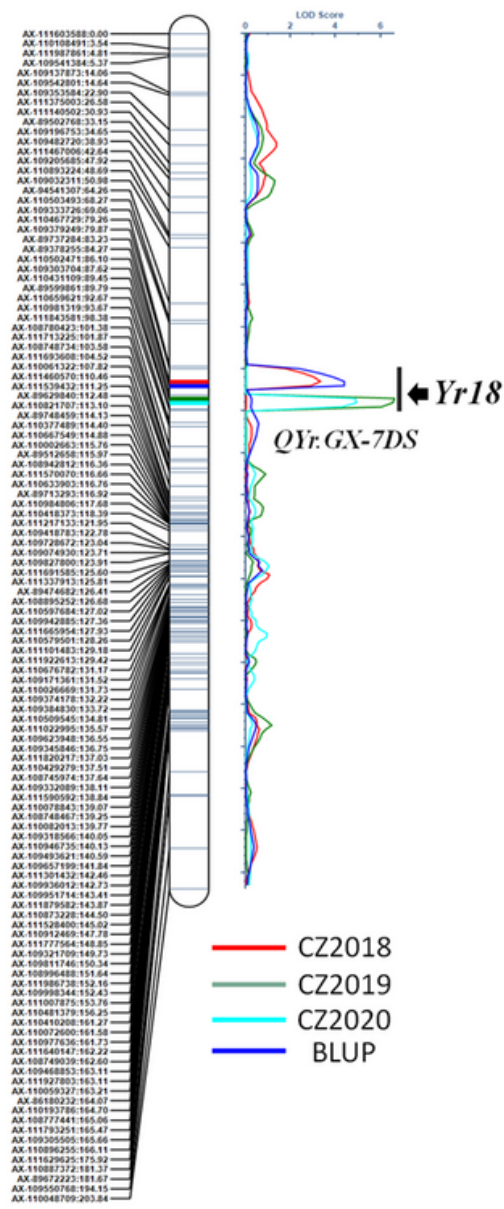

C

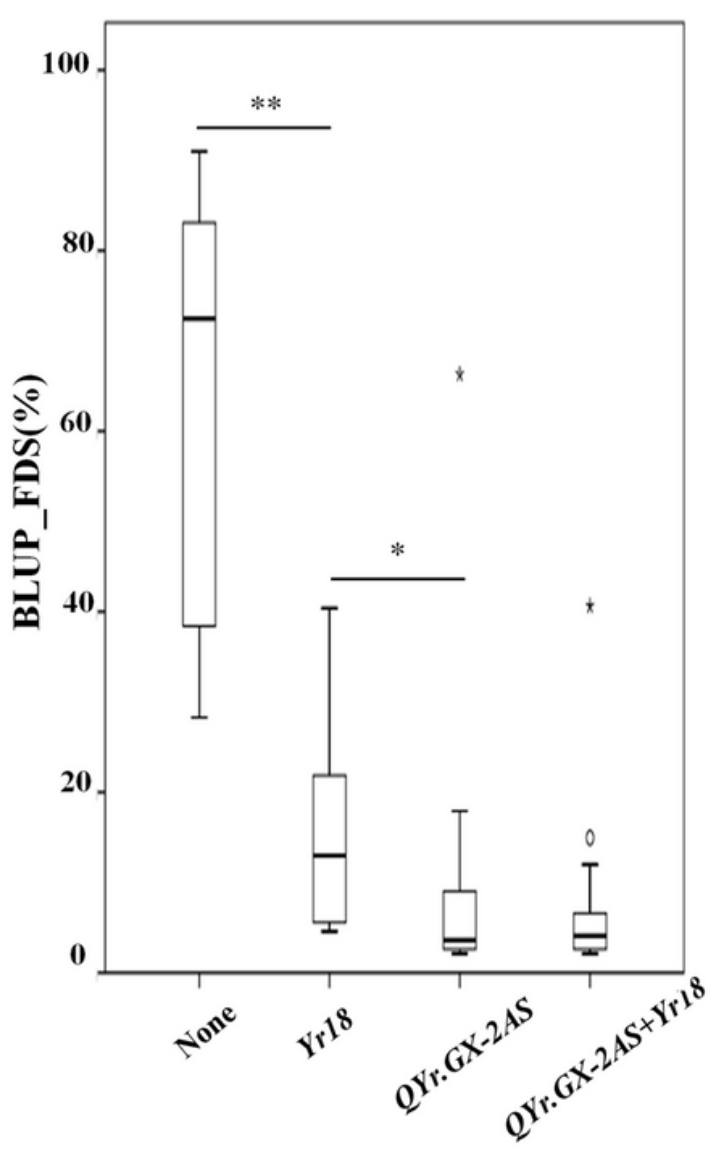

Figure 3

QTL conferring adult plant stripe rust resistance detected by inclusive composite interval mapping (ICIM) in the RILs population from Gaoxianguangtoumai (GX) × Taichung 29 (TC 29). Graphical displays of QTL (a) QYr.GX-2AS and (b) QYr.GX-7DS detected on chromosome 2A and 7D based on the final disease severity (FDS) from three field trials and BLUP data. The box plots for final disease severity (FDS) based on the BLUP data associated with the two loci (QYr.GX-2AS and Yr18) and their combination in the Gaoxianguangtoumai (GX) × Taichung 29 (TC 29) RIL population (c). 
a

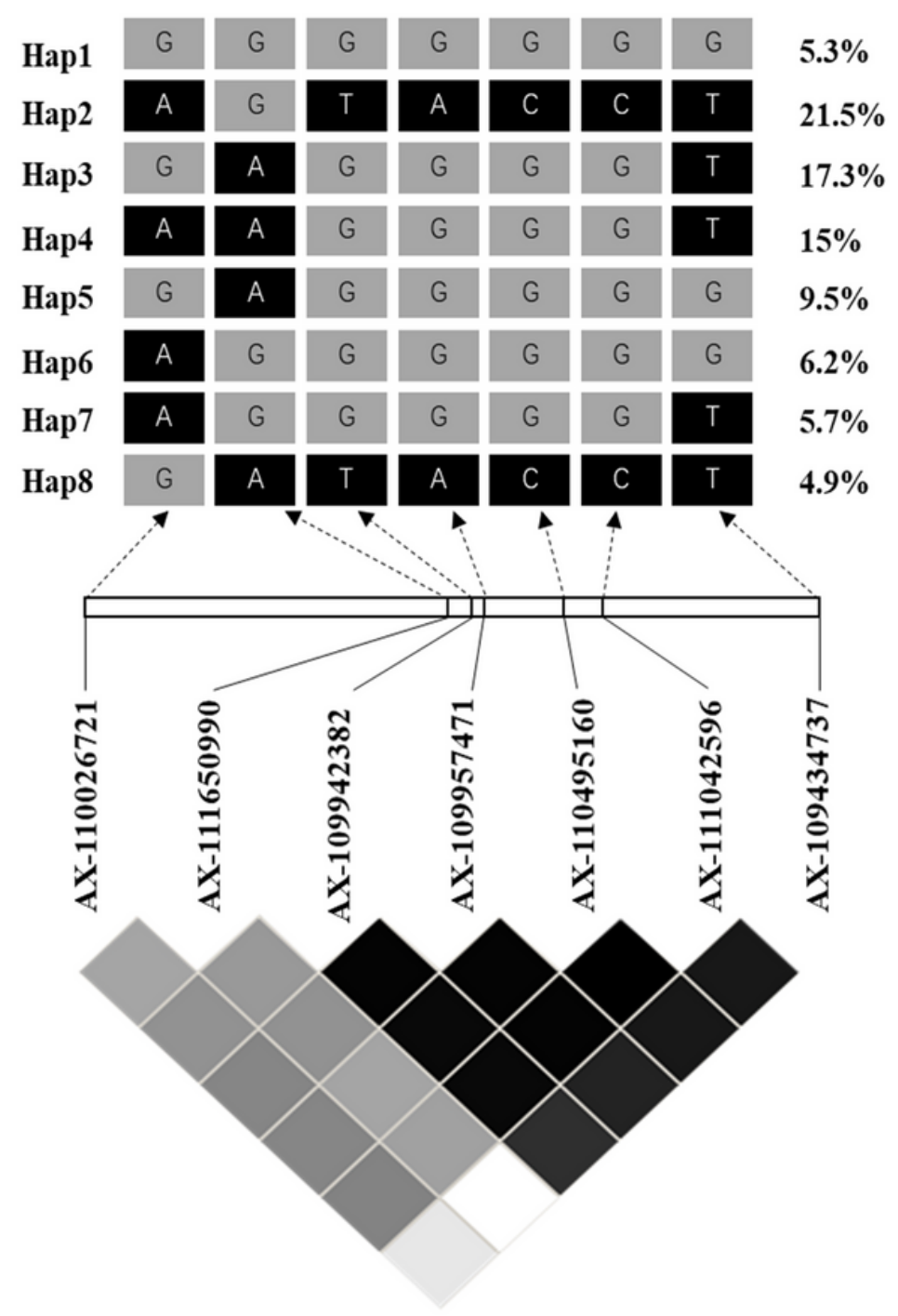

b

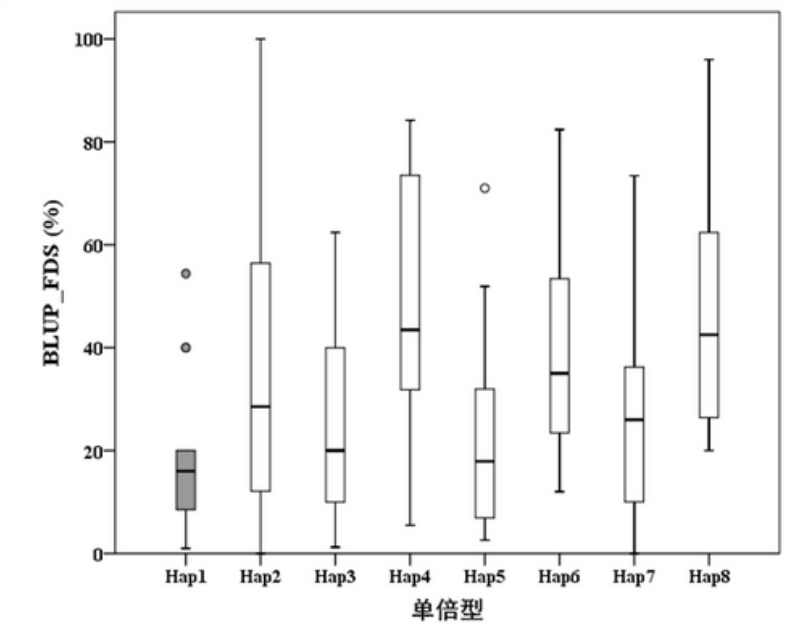

C

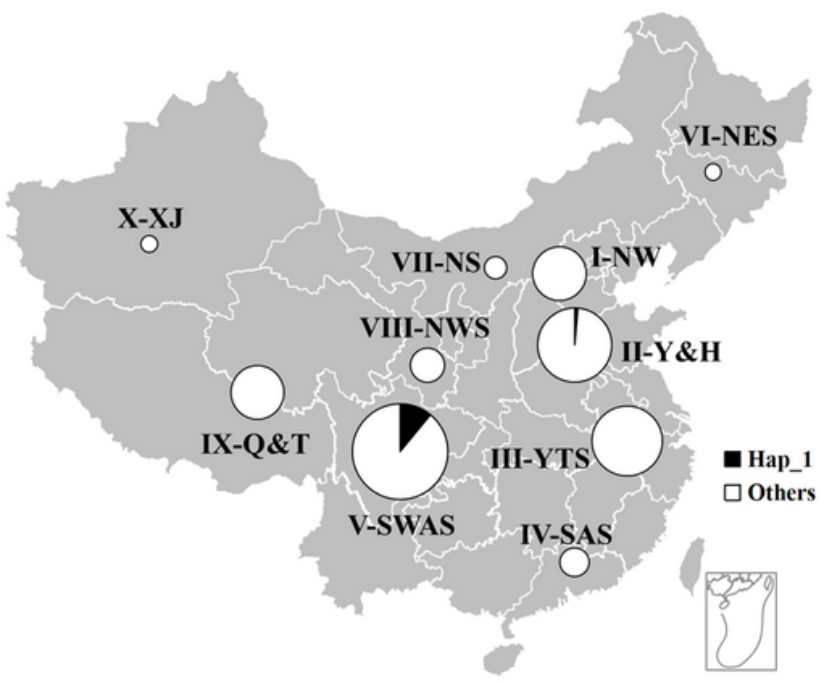

Figure 4

Haplotype analysis of QYr.GX-2AS associated with stripe rust resistance in 325 Chinese wheat landraces. (a) LD heatmap surrounding QYr.GX-2AS. The number on the right shows the distribution frequency of 8 haplotypes in these Chinese wheat landraces. (b) Boxplot displays the mean final disease severity of the accessions carrying different haplotypes. (c) Frequencies of resistance allele of QYr.GX-2AS in Chinese wheat landraces in ten major agro-ecological production zones of China. 
a

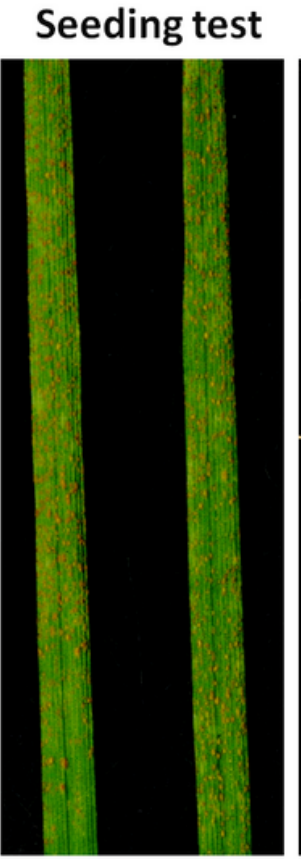

NIL-R NIL-S
Adult-plant test

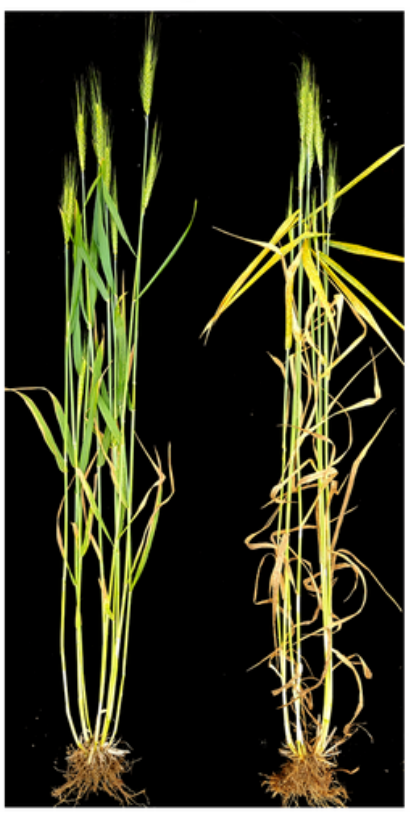

NIL-R b

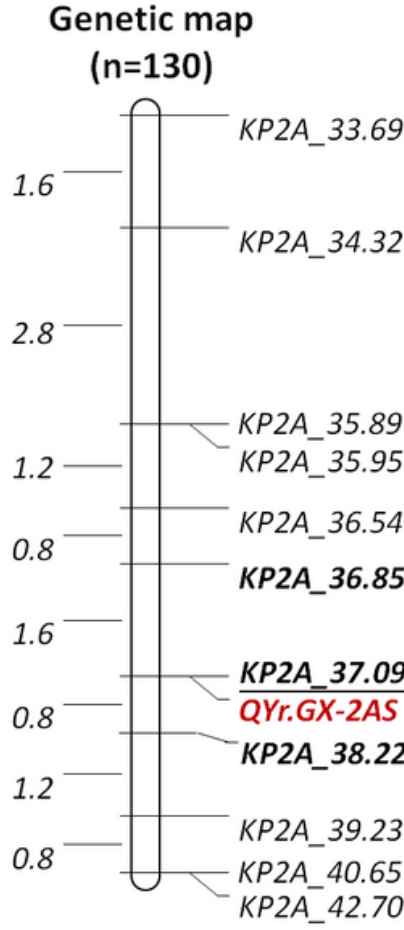

C

\section{Candidate region}

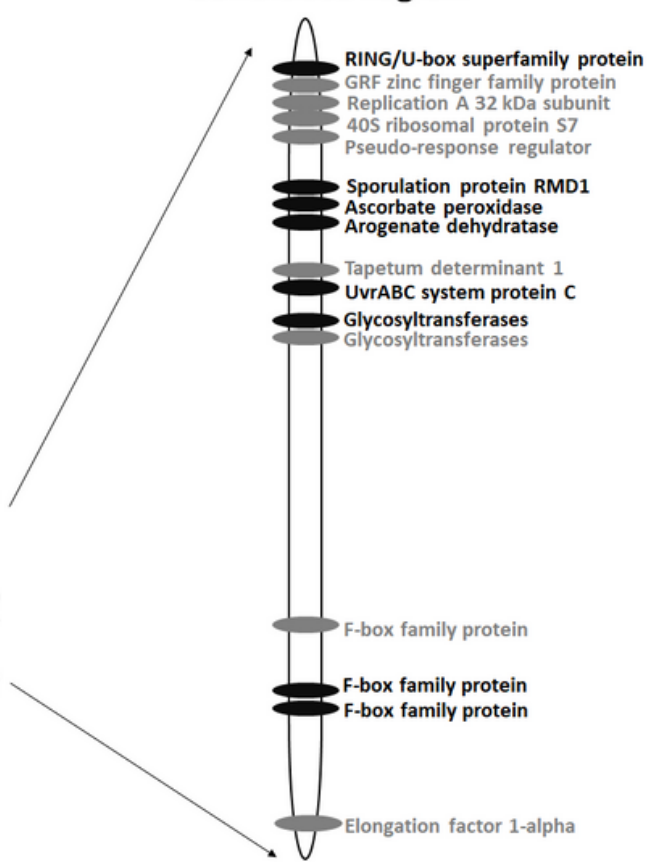

Figure 5

Stripe rust response of the near-isogenic lines with mixture Pst at the adult-plant stage in the field (a), genetic map of chromosomes 2AS showing locations of stripe rust resistance genes QYr.GX-2AS based on the NIL-derived population (b), predicted genes in IWGSC RefSeq v1.1, highlight in black showed non-synonymous variants between Gaoxianguangtoumai (GX) and Chinese Spring in the exon regions (c). 
A QTL hot-spot region

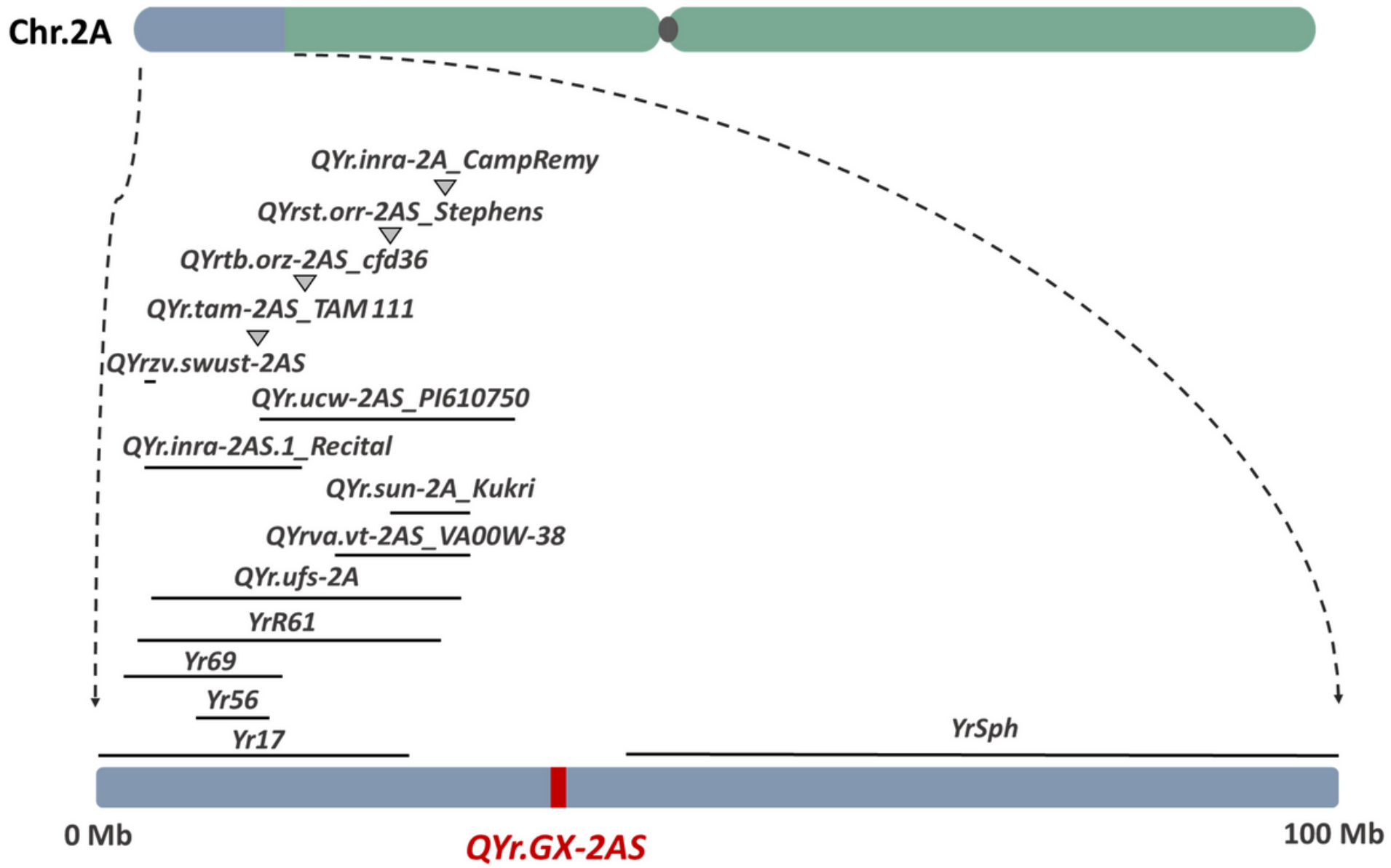

Figure 6

Comparison of QYr.GX-2AS with previously identified genes/QTL (from biparental population) for resistance to stripe rust based on the reference genome of bread wheat (IWGSC, RefSeq v1.0).

\section{Supplementary Files}

This is a list of supplementary files associated with this preprint. Click to download.

- SupplementaryFigure.pdf

- SupplementaryTables.xIsx 